\title{
RELATIONSHIP BETWEEN PARTICIPATORY DECISION MAKING AND JOB SATISFACTION: A CASE STUDY OF PRIVATE SECTOR ORGANIZATIONS IN KURDISTAN-LFU
}

\author{
Hazhar Omer Mohammed \\ Department of Legal Administration, Lebanese French University, Kurdistan Region, Iraq \\ E-mail: hazharbus@gmail.com
}

\begin{abstract}
The research examines relationships between Participation in Decision Making (PDM) and job satisfaction amid educational staff in private organization sector in Kurdistan region Lebanese French University (LFU). This research was showed Behavioral on the positive method to the study. The study approved a quantitative survey research design. The area of the study including all management member stuff of the LFU private university of Kurdistan region. arranged survey questionnaire was organized and distributed to all respondents which is a member of the organization. The study includes of two main variables that is job satisfaction which was the dependent variable and PDM, which was the independent variable. Moreover, four-point scale was used to collect data and analysis was based on frequency, bivariate correlation, coefficient and linier regression. A strong relationship was found between PDM and job satisfaction in context of decision making among their organization with the correlation rate of consultation $\left(r=.616^{* *}\right)$, problem solving and engagement $\left(r=.736^{* *}\right)$, informative decision $\left(r=.815^{\star *}\right)$ and job satisfaction $\left(r=>1^{* *}\right)$ which is dependent variable. According the study level of satisfaction of the workers increase on participatory decision making.
\end{abstract}

\section{KEY WORDS}

Job satisfaction, decision making, participatory, private sector, organization.

Globalization affected everything in the world and changes always. Also, business, organizational flow and work flow as important aspects in the world of business has been affected by globalization to meet the running requirement, challenges of new world systematic methods and effectiveness of their workflow (DeSantis \& Durst, 1996). Always, these changes run by humans by trying to implement in standard patterns in away sometimes in systematic farms and sometime in manual methods. For meeting of targets and facing of new challenges every department play a very important part for growing and developing of their business and outcome results always done by team efforts and effectiveness. Human resources and industrial relations department always played very important role for merging of team and hiring of perfect candidate in exact position for getting up to the mark performance and results. Every industry wants loyalty from their employees with best performance. For getting results they provide high purges, increments, promotions acceptance of employee work and their participation in an organizational projects or regular job duties. When employee gets benefits of their work, they feel comfortable and outcome result became very positive, more recognizable and beneficiary for industry/organization. For employees Participation in any department or organizational forum is very important and played a key role for their career. Further, participation in any decision-making job will be a glory for employees and make then in comfort zone. On other hand, everyone tries to play an important role within department or within industry/ organization (Tietjen \& Myers, 1998).

Job satisfaction and participation in business always enhance the ability of work and outcome results are always positive for both ends of employee and employers. In our case we submitted some questionaries' to the employees of LFU in Kurdistan region for observing how many employees participate in decisions, how many employees were satisfied with their jobs and how many employees can benefit after doing some extra ordinary activeness (laffaldano \& Muchinsky, 1998). 
In this theses we try to found out the results and trying to prove with some practical results why PDM and job satisfaction is very necessary and import for both employee and employer. Good human resource \& managerial decisions how change the shape of any industry. How satisfying employees affect industry and organization in the contest of their good work. How industry can get more benefits by providing their employees a benefits and comfort zone including job security. The objective of the research is to examine the relationships between PDM and job satisfaction amid educational staff in private organization sector in Kurdistan region - LFU.

\section{LITERATURE REVIEW}

There are many researches that have been done in the past relation to participatory decision making and job satisfaction. The researcher has selected few of them as mention below.

Programmed and non-programmed are the definition of the rate and the face of decision in the decision making filed. Decision rules can be improved by the reputation of the programmed decision most enough. The decision makers can have a clear idea to choose alternative through the decision rule whenever the condition has predefined by the decision makers and a fit rule will choose once the same condition is met. Programmed decisions familiar as highly organized which mean aims are well-defined and clear, the process of the decision making has been proven and the data channels and reference well-known (Zubair et al. 2015).

Uniqueness and non-encountered of problems or conditions are known as nonprogrammed decisions when the decision is made which needs problem solving process. Problem solving can be counted as one of the special method of decision making which means the problem is rare, so these kind of problems needs improving and assessing without the help of decision rules. Moreover, the clear-cut of the data and information plus the non-clear process make the non-programmed decisions be unwell structured, then in this case the aims mostly be unclear (Moorhead \& Griffin, 2004).

As Cohen, Bennet (1997) state that, levels of decisions making are classified to four types (strategic decisions, tactical decisions, operational decisions and policies). First of all, wide decisions around the organization's direction and the relationships with the outside world counted as strategic decisions. The organizational objectives have been established by these decisions and agendas will be executed for directing the activities of the organization. As a level these decisions will made by the senior management (Cohen \& Bennett, 1997).

Despites of, operational decisions are stock levels length production which run by the minor administrative mainly contain daily activities (Cohen \& Bennett, 1997). The decisions of a specific task or action define as policies when a set ground instructions and principles has been applied which will be the level of decision making.

As study mentioned that the approaches of decision making are divided in two main part in any organization. The first way is authoritarian approach which the decision made by an executive figure for the group in a way the group decides what should be done which means the decision will be made by the manager based the knowledge has been gathered as an experience. Then, the decision should be clarified by the manager to the group in order to collect their acceptance of it. The group is the second approach of decision making where the group proposes idea, examines and agrees upon a decision to implement (Muindi, 2011).

In most cases, employees are asked about their point of view regarding the working style that does not specifically affect the employer's decision. Different strategies could be used for implementation of consultation. Process of consultation improves business in different ways, and it also creates harmony among employees and employer. Where operational matters are concerned, consultations lead to participation in decision making (Cole, 1997). The employees confident and they feel themselves worthy if they got job enrichment, it does not only create confidence but enhance the quality and quantity of work and it improves the quality of decisions taken. However, it does not offer real opportunities to 
participate in even the operational decisions taken in the organization (Graham \& Bennet,1998).

Delegation of power causes the participative management style. Employees might get chance to participate in the decision making that have a concrete effect on their work, in general it is a patronizing method through which employees can express their views. However, where a bona fide approach to participation is adopted, then it is likely that employees will in fact become 'empowered' by being able to fully share in decisions affecting their immediate work (Graham \& Bennet, 1998; Cole, 1997).

An organization can be equipped with various benefits by participative style. According to Rice (1987) If decision is being done on the actual spot of performance that would be very beneficial. Participation in decision making leads to harmony in the organization (Ward \& Pascarelli, 1987) and improves staff morale and support (Pashiardis, 1994). By ensuring every employee that his presence and output plays an important role in achieving the mutual exclusive goals of the company and themselves, can only be obtained through participative style. Employees feel themselves as a stakeholder of an organization when their views are listened and considered. Managers can change the thinking of employees to accept any change if they are being allowed to speak in such matters. Any change can be effectively implemented by this way. Through these style employees are well aware about any upcoming change that could might affects them or not. Organization should create a culture of dynamic approach rather than responsive approach (Helms, 2006).

According to Cole (1997), some managers are not very keen to share strategic decisions that could be caused by different reasons, one of which is to keep the strategies undisclosed and other can be to protect organization to face the unviable consequences. In every case participative style does not cover the problems of any organization. Every manager should carefully understand this style in every aspect. Pashiardis (1994) in the article, 'Teacher Participation in Decision Making', mentioned that, organizational policies should be in line with this style, and all required components should be organized and implemented for successful implementation of participative style.

One thing that is very important for an employee is job satisfaction. For both employee and employer job satisfaction carries equal importance, from employee prospective, employee feel himself secure and in return he fulfills his duties with due care and for employer an active and productive work by an employee is the only thing that is needed (Muindi, 2011). The studies of Hawthorne related to job satisfaction was an important step. These studies (1924-1933), primarily credited by (Mududa, 2014) of the Harvard Business School, is related to the effective and productive work of an employee. By changing novel changes occur in productivity of an employee (called the Hawthorne Effect). People do not only work for pay, there are some other factors that encourage a person to do job.

Job satisfaction is also affected by scientific management (also known as Taylorism). According to Taylor's, (1998) book, Principles of Scientific Management, every task has a way to be well performed. This book highlighted the different styles at work place, as assembly lines and hourly wages. That technique was very effective initially but with passage of time it becomes reluctant and some other factors arises that were unanswered. Maslow's Hierarchy of need theory of motivation also laid the foundation for job satisfaction theory. This theory explains that people seek to satisfy five specific needs in life - physiological needs, safety needs, social needs, self-esteem needs, and self-actualization. This theory was somehow better than the early studies, according to views of different scholars there are different factors such as higher pay, participative management style, being involved during management decisions, that increases the job satisfaction for an employee. However, every employee has its own scale of job satisfaction (Anderson et al. 1984; Prabhu et al. 2019). According to Armstrong (2006) Job satisfaction is basically the fulfilment of one's expectations from the specific job and job dissatisfaction results in absenteeism and turnover.

Satisfaction is very clearly defined by different theories. These are: Maslow's theory, Equity Theory, Value Theory, Discrepancy Theory, Vroom's Expectancy Theory and Hertzberg's two factors theory. For this study, Hertzberg's two factor theory will be 
considered. According to those theory two factors affects the satisfaction and dissatisfaction. These were termed as satisfiers (or motivators) and dissatisfies (or hygiene factors). According to Armstrong (2006) and Cole (2002) the factor that pushes a person to perform his duties in a good manner is motivators that are directly related to the content of job. Motivators could be recognition, autonomy, self-esteem, and work. On other side hygiene includes factors that cause dissatisfaction to a person that could be company's policies, administration and the context of the job. They observe that motivators appeared to produce motivated behavior while hygiene factors produced either dissatisfaction or no response. In nutshell the motivators factors exist long term because they are self-adopted while hygiene factors are for short term because they are effective from outside and they are the aggressive and immediate response.

Herzberg et al. (1957) argued that answering question, "what does the worker want from his/her job?", is a way to measure the job satisfaction. That will assist management to search for new methods of motivation for employees. Highly motivated employees are more concerned about the quality of work and their commitment towards organization. Organizations are more concerned about the job satisfaction of employees. Employees turnover is a measure of job satisfaction. Luthans et al. (2005), argued that job satisfaction can only be measured by self-examination, some methods can be used to measure job satisfaction as rating scales, critical incidents, interviews and action tendencies.

Rating scale is the most effective way to measure job satisfaction. Question can be related to remuneration, work environment, the way of work and co-workers. Some question are close ended questions that can be only responded by YES or NO, other method can be offer a range of digits from 1-5, 1 the least and 5 the most. One of the most popular rating scales is the Minnesota Satisfaction Questionnaire (Weiss et al. 1967). MSQ provides a tool to measure satisfaction and dissatisfaction. Minnesota Satisfaction Questionnaire is very credible design backed by different scholars (Albright, 1972; Anderson et al. 1993; Brown et al. 1998; Decker \& Borgen, 1993; Levinson et al. 1988; Khan \& Abdullah 2019; Ganeshkumar et al. 2019).

Various authorities claimed that job satisfaction is affected by relationship between work environment and job satisfaction. Perceived job satisfaction can be obtained by management style and job design. According to Herzberg et al. (1957) Job satisfactions is affected by responsibility, degree of freedom to act rewards and quality of supervision. Different studies show that commitment can be achieved by participative style. Making and executing a decision more successfully is done by the persons who feel themselves responsible while they were in a part of decision making. By participating in decision making, employees may better understand linkage between their performance and rewards they want most (Moorhead \& Griffin, 1989). Employees performance and job satisfaction is highly effected by participative style. However (Guion, 1998) notes that the degree of satisfaction will depend on individual needs and expectations, and the working environment. Some questions should be answered to measure the job satisfactions, according to these studies, some questions are Do employees participate in decisions making? Do the level of pay, the work itself, responsibility, achievement, recognition, opportunity for growths, supervision, work groups and working conditions determine job satisfaction? Does Employee participation in decision making increase intrinsic and extrinsic job satisfaction?

$\mathrm{H} 1$ : There is a positive relationship between employee's consultation and job satisfaction.

Improve management performance and decision making encourages the environment for employees to provide their input that could be helpful for managers and supervisors during implementation of new practices and procedures. improve employees' performance and commitment- performance of employees could be better if they are clear about their responsibilities and proper information is being provided to them, further, if they are very clear about the goals of organization. help develop greater trust - providing an opportunity for each employee to express their issues can make a better relation between employee and employer. increase job satisfaction - motivation within employees can be achieved only when they can better understand their work and position within organization. encourage a 
more flexible working environment - Work-life balance can be made better by employers if they promote a culture of flexible working policies and practices.

$\mathrm{H} 2$ : There is a positive relationship between employee's problem solving engagement and job satisfaction.

Interactive mode is active when employee is engaged in work, it comprised of all kinds of challenges and inspiration, it also provides job satisfaction to employees. According to Lu et al. (2016) work engagement is comprised of individual dimensions, and job satisfaction is the outcome of these dimensions. As per Karanika et al. (2015) employees, who are strongly and positively engaged to their work and show energy and dedication to their work, consequently, have satisfaction with their job. Garg et al. (2017) found that employees, who have high level of engagement with their work and the organizations, get negatively affected by negative events they encounter while working and consequently are affected by workrelated stressors.

H3: There is positive relationship between informative decision and job satisfaction.

If we compare the past and present situation of organizations with regards to their employees' in past organization secures loyalty of employees by giving them job security in present organizations are adopting different policies in response of their competitors as downsizing and restructuring (Madi et al. 2012). Maintaining employee organizational commitment remains one of the challenges faced by organizations in this competitive world (Bergmann et al. 2000). Organization wants to maintain its commitment with employees by its existence (Yavuz, 2010). As such, organizational commitment is the level of allegiance an employee feels for his employer (Demirel \& Goc, 2013; Khan \& Abdullah 2019). If employees have strong commitment with organization, they are more productive and more responsible towards their work (Demirel \& Goc, 2013; Khan et al. 2019). Relationship between job satisfaction and organizational commitment has been studies by many of experts, they concluded it as, they both have almost same affect, which is important for employees and organization success (Bodla \& Danish, 2009). As such, these variables - job satisfaction \& organizational commitment are even more significant to study in higher education institutions. In the South African higher education context, Mabasa \& Ngirande, (2015) suggests that, higher education plays an important role in human development and human resources management.

\section{METHODS OF RESEARCH}

This research has been done by using quantitative research method. The items of this study adopted from Pacheco \& Webber (2012). Moreover, it focuses on payment, rewards, skills, encourage, connection, opportunities, relationship and satisfactions. Furthermore, the most satisfaction points are, job satisfaction, problem solving engagement, consultation and informative decision. Thus, all these items that have been used inside the questionnaires had been matched and redesigned according to the Lebanese French University in order to make it more relevant. The data which is being used in this study is collected from different staff of the Lebanese French University. These employees are varying among their roles and education level. The researcher collected data for 63 respondents and applied statistical tools like correlation analyses for analyzing the data with the SPSS version 22 software package. The factors were deemed to be most relevant to keenly observe, understand and give any fruitful results. In the context of this study Stratified sampling was used in this study. The given questionnaires have been designed for two-part personal detail and general question. The personal details include age, gender, education level, position and work experience. Additionally, this study mainly focuses on level of education and work experience due to the level of participant. Also, general questions are a part of the questionnaires which contain dependent and independent variable. Dependent variable is job satisfaction and independent variable is decision making. The study combines consultation, problem solving engagement and informative decision under independent variables. If we examine the data in context of "Level of Education", the persons participated in the survey presents their point of view in relevancy of all hypothetical factors directly correlated with Job satisfaction as, PhD 
(34.9\%) while Masters (46\%) and Bachelor (17.5\%). Moreover, if the data is being observed within Context of their "Position", the results were as Top-Level Manager (38.1\%), Manager (23.8\%) and Assistant Manager (19\%).

\section{RESULTS AND DISCUSSION}

The result of the analysis demonstrates a positive correlation $\left(r=.616^{* *}, n=63, p<.01\right)$ between consultation and job satisfaction at 0.01 level (2-tailed).

Table 1 - Correlation between Consultation and Job Satisfaction

\begin{tabular}{|c|c|c|c|}
\hline \multirow{2}{*}{ Correlations } & Consultation & Job Satisfaction \\
\cline { 2 - 4 } Consultation & Pearson Correlation & 1 & 0.616 \\
\hline \multirow{2}{*}{ Job Satisfaction } & Sig. (2-tailed) & & .000 \\
\cline { 2 - 4 } & Pearson Correlation & 0.616 & 1 \\
\hline
\end{tabular}

** Correlation is significant at the 0.01 level (2-tailed).

In the above table 1 revealed that $\mathrm{H} 1$ : "There is a positive relationship between consultation and job satisfaction". In this case the studies refer the fact that if the style of working conditions is job satisfaction and consultative then it would allow organization to work in a successful way.

Table 2 - Correlation between Problem Solving Engagement and job satisfaction

\begin{tabular}{|c|c|c|c|}
\hline \multicolumn{2}{|c|}{ Correlations } & Problem Solving Engagement & Job Satisfaction \\
\hline \multirow{2}{*}{ Problem Solving Engagement } & Pearson Correlation & 1 & $0.736^{\prime \prime}$ \\
\cline { 2 - 4 } & Sig. (2-tailed) & & 0.000 \\
\hline \multirow{2}{*}{ Job Satisfaction } & Pearson Correlation & 0.736 & 1 \\
\cline { 2 - 4 } & Sig. (2-tailed) & 0.000 & \\
\hline
\end{tabular}

${ }^{* *}$ Correlation is significant at the 0.01 level (2-tailed).

Table 3 - Correlation between Informative Decision and Job Satisfaction

\begin{tabular}{|c|c|c|c|}
\hline \multicolumn{2}{|c|}{ Correlations } & Informative Decision & Job Satisfaction \\
\hline \multirow{2}{*}{ Informative Decision } & Pearson Correlation & 1 & $0.815^{* \prime}$ \\
\cline { 2 - 4 } & Sig. (2-tailed) & & 0.000 \\
\hline \multirow{2}{*}{ Job Satisfaction } & Pearson Correlation & 0.815 & 1 \\
\cline { 2 - 4 } & Sig. (2-tailed) & 0.000 & \\
\hline
\end{tabular}

** Correlation is significant at the 0.01 level (2-tailed).

In the table 2 , there is also strong and positive correlation $\left(r=.736^{* *}, n=63, p<.01\right)$ between Problem Solving Engagement and job satisfaction at 0.01 level (2-tailed). Thus, H:2, "There is positive relationship between Problem Solving Engagement and job satisfaction". This study reveals the positive and strong relationship between two factors that play a vital and important role in job satisfaction and organizational behavior towards the prosperity of an organization. Many of experts are of the view that job satisfaction cannot be obtained by implementing either only one factor affecting that directly. A suitable mix is necessary to being placed in a structured manner to get the desired results.

In the table 3 , there is moderate and positive correlation $\left(r=.815^{* *}, n=63, p<.01\right)$ between Informative Decision and Job satisfaction at 0.01 level (2-tailed). Thus, $\mathrm{H}: 3$, "There is positive relationship between Informative Decision and Job satisfaction". According to this study there is strong and positive relationship between these two variables. If the organizations deal with the problem through 360-degree problem solving technique, the result would be very effective and positive. 


\section{CONCLUSION}

Decision making play a profound role in any industry and organization in term of making the industries more professional and more suitable for employees. Moreover, having such an environment helps employee to be more productive which leads to run any industry quite smooth. Nowadays, quality of organization evaluated by the participating in decision making of all employees in the all department of the organization. Organizations will be more reliable if and only if let their employee to decide upon issues, internal threats and external threats that face the organization. Despite of organization which does not let employees to participate in decision making counted as not reliable organization. This study has been done for clarifying the relationship between participatory decision making and job satisfaction. Job satisfaction includes all facilities that make an employee to be productive and achieve organization goals. Moreover, reviewing old researches has been done for make sure there are relationships between participatory decision making and job satisfaction. Besides that, questionnaire has distributed among academic staff of private organization sectors in KRG for instance, LFU. However, this study contains three hypotheses. After analyzing the data which has been given from participants we understood that there are strong relationships between participatory decision making and job satisfaction. Results contain consultation, problem solving engagement and informative decision making among job satisfaction. the result of the mentioned dependent variables and independent variable show that employee has a profound impact on decision making and job satisfaction in their organization.

\section{REFERENCES}

1. Albright, D. W. (1972). Expectancy theory predictions of the satisfaction, effort, performance, and retention of naval aviation officers. Organizational Behavior and Human Performance, 8(1), 1-20.

2. Albright, D. W. (1972). Expectancy theory predictions of the satisfaction, effort, performance, and retention of naval aviation officers. Organizational Behavior and Human Performance, 8(1), 1-20.

3. Anderson, W. T., Hohenshil, T. H., \& Brown, D. T. (1984). Job satisfaction among practicing school psychologists: A national study. School Psychology Review, 13, 225230.

4. Anderson, W. T., Hohenshil, T. H., \& Brown, D. T. (1984). Job satisfaction among practicing school psychologists: A national study. School Psychology Review.

5. Anderson, W. T., Hohenshil, T. H., \& Brown, D. T. (1984). Job satisfaction among practicing school psychologists: A national study. School Psychology Review, 13, 225230.

6. Anderson, W. T., Hohenshil, T. H., \& Brown, D. T. (1984). Job satisfaction among practicing school psychologists: A national study. School Psychology Review.

7. Armstrong, M. (2006). A handbook of human resource management practice. Kogan Page Publishers.

8. Armstrong, M. (2006). A Handbook of Human Resource Management Practice. Human Resource Management, edition 10, 123-134.

9. Armstrong, M. (2006). A handbook of human resource management practice. Kogan Page Publishers.

10. Armstrong, M. (2006). A Handbook of Human Resource Management Practice. Human Resource Management, edition 10, 123-134.

11. Bergmann, T. J., Lester, S. W., De Meuse, K. P., \& Grahn, J. L. (2000). Journal of Applied Business Research,. (16)3, 15-26.

12. Bergmann, T. J., Lester, S. W., De Meuse, K. P., \& Grahn, J. L. (2000). Integrating the three domains of employee commitment: An exploratory study. Journal of Applied Business Research, 16(4), 15-26. 
13. Bodla, M. A., \& Danish, R. Q. (2009). Politics and workplace: an empirical examination of the relationship between perceived organizational politics and work performance. South Asian Journal of Management, 16(1), 44-62.

14. Bodla, M. A., \& Danish, R. Q. (2009). Politics and workplace: an empirical examination of the relationship between perceived organizational politics and work performance. South Asian Journal of Management, 16(1), 44-62.

15. Brown, M. B., Hohenshil, T. H., \& Brown, D. T. (1998). Job satisfaction of school psychologists in the United States: A national study. School Psychology International, 19(1), 79-89.

16. Brown, M. B., Hohenshil, T. H., \& Brown, D. T. (1998). Job satisfaction of school psychologists in the United States: A national study. School Psychology International, 19(1), 79-89.

17. Cohen, D. J., \& Bennett, S. (1997). Human Perception and Performance Why can't most people draw what they see? Journal of Experimental Psychology, 23(3), 609-621.

18. Cohen, D. J., \& Bennett, S. (1997). Human Perception and Performance Why can't most people draw what they see? Journal of Experimental Psychology, 23(3), 609-621.

19. Cole, G. (1997). Personnel Management: Theory and Practice. Thomson learning 2002, 5th edition, 27.

20. Cole, G. (1997). Personnel Management: Theory and Practice. Thomson learning 2002, 5th edition, 27.

21. Cole, G. (2002). Personnel and Human Resource Management. Cengage Learning EMEA, 5, 14.

22. Cole, G. (2002). Personnel and Human Resource Management. Cengage Learning EMEA, 5, 14.

23. Decker, P. J., \& Borgen, F. H. (1993). Dimensions of work appraisal: Stress, strain, coping, job satisfaction, and negative affectivity. Journal of Counseling Psychology, 40(4), 470.

24. Decker, P. J., \& Borgen, F. H. (1993). Dimensions of work appraisal: Stress, strain, coping, job satisfaction, and negative affectivity. Journal of Counseling Psychology, 40(4), 470.

25. Demirel, Y., \& Goc, K. (2013). The impact of organizational commitment on knowlegde sharing. European Scientific Journal, ESJ, 9, 19.

26. Demirel, Y., \& Goc, K. (2013). The impact of organizational commitment on knowlegde sharing. European Scientific Journal, ESJ, 9, 19.

27. DeSantis, V. S., \& Durst, S. L. (1996). Comparing job satisfaction among public-and private-sector employees. 26(3), 327-343.

28. DeSantis, V. S., \& Durst, S. L. (1996). Comparing job satisfaction among public-and private-sector employees. 26(3), 327-343.

29. Ganeshkumar, C., Prabhu, M \& Nabaz Nawzad Abdullah. (2019). Business Analytics and Supply Chain Performance: Partial Least Squares-Structural Equation Modeling (PLSSEM) Approach, International Journal of Management and Business Research, 9(1), 9196

30. Garg, Kanika,Dar, Ishaq, Mishra, Mridula. (2017). Job Satisfaction and Work Engagement: A Study Using Private Sector Bank Managers. book, 235-243.

31. Graham, H \& Bennet, R. (1998). Human Resource Management. Pearson Education Limited $01 \mathrm{Dec}$ 1998, 9th edition.

32. Guion, R. (1998). The role of perception in the sound change of velar palatalization. Personnel Psychology, 55(1-2), 18-52.

33. Helms, M. M. (2006). Theory X and Theory," Encyclopedia of Management. Education.Retrieved November 1, 2008, pp.11-13.

34. Herzberg, F., Mausner, B., \& Peterson, R. 0., \& Capwell, DF . (1957). Job attitudes: Review of research and opinion. Pittsburgh: Psychological Service of Pittsburgh. New York: Wiley, pp.138-152.

35. laffaldano, M. T., \& Muchinsky, P. M. (1998). Job satisfaction and job performance: A meta-analysis. 97(2), 251. 
36. Karanika-Murray, Maria, Michaelides, George. (2015). PURPOSE - Although both job design and its broader context are likely to drive motivation, little is known about the specific workplace characteristics that are important for motivation. The purpose of this paper is to present the Workplace Characteristic. Journal of Organizational Effectiveness: People and Performance, 2, 224-243.

37. Khan, S. I \& Abdullah, N.N. (2019). The effect of ATM Service quality on customers satisfaction and loyalty: An Empirical Analysis, Russian Journal of Agricultural and SocioEconomic Science, 5(89), 227-235

38. Khan, S. I \& Abdullah, N.N. (2019). The Impact of staff training and Development on teacher's productivity. Economic, Management and Sustainability, 4(1), $37-45$.

39. Khan, S. I., Sultan A. A., and Alsamarai S. (2019). Social media and its adverse effect on academic performance of students. Bulletin of Social Informatics Theory and Application, $3(1), 38-44$.

40. Levinson, E. M., Fetchkan, R., \& Hohenshil, T. H. (1988). Job satisfaction among practicing school psychologists revisited. Job satisfaction among practicing school psychologists revisited, (6)2, 365.

41. Lu Lu et al , Gursoy, \& Neale. (2016). Work engagement, job satisfaction, and turnover intentions: A comparison between supervisors and line-level employees. International Journal of Contemporary Hospitality Management, 28, 58-71.

42. Luthans, F., Avolio, B. J., Walumbwa, F. O., \& Li, W. (2005). The psychological capital of Chinese workers: Exploring the relationship with performance. Management and Organization Review, 1(2), 249-271.

43. Mabasa, F. D., \& Ngirande, H. (2015). Perceived organisational support influences on job satisfaction and organisational commitment among junior academic staff members. Journal of Psychology in Africa, 25(4), 364-366.

44. Madi, M., Abu-Jarad, I., \& Alqahtani, A. H. (2012). Employees' perception and organizational commitment: A study on the banking sector in Gaza, Palestine. International Journal of Business and Social Science, 3, 16.

45. Moorhead, G. \& Griffin, R. (1989). Organisational Behaviour. Boston, Houghton Mifflin Company, 2nded, 11.

46. Moorhead, G. and Griffin, R. (2004). Organisational Behaviour: Managing People and Organisations. Scientific Research an academic publisher journals, 8, 306-321.

47. Mududa, E. O. (2014). Employing Trained Personnel for Improved Job Satisfaction: A Case Study of the Kenya Civil Service. Routledge ,University of Nairobi, edition 12, 187.

48. Muindi, F. K. (2011). The relationship between participation in decision making and job satisfaction among academic staff in the school of business, university of Nairobi. Journal of Human Resources Management Research, 3-34.

49. Muindi, F. K. (2011). The Relationship between Participation in Decision Making and Job Satisfaction among Academic Staff in the School of Business, University of Nairobi. Journal of Human Resources Management Research, Vol. 2011 (2011), 15-34.

50. Pacheco, G., \& Webber, D. J. (2012). Culture, participative decision making and job satisfaction. The International Journal of Human Resource Management, 23(13), 26612679.

51. Pashiardis, P. (1994). Teacher Participation in Decision Making,. International Journal of Education Management, 8(5), 14-17.

52. Prabhu, M., Nabaz Nawzad Abdullah and Madan Mohan, G. (2019), An Empirical Study on the Satisfaction Level of National and International Tourists towards Natural Attractions in Kurdistan. African Journal of Hospitality, Tourism and Leisure, 8 (2), 1-8.

53. Rice, R. E. (1987). Managing organizational innovation: The evolution from word processing to office information systems. Columbia University Press.

54. Taylor's, F. W. (1998). The principles of scientific management. 1911. In T. p. management.. Routledge.

55. Tietjen, M. A., \& Myers, R. M. (1998). Motivation and job satisfaction. 36(4), 226-231.

56. Ward, B., \& Pascarelli, J. (1987). Networking for Educational Improvement,' in Goodlad. The Ecology of School Renewal, Chicago University Press, Chicago, J.I. (Ed.), 192-209. 
57. Weiss, D. J., Dawis, R. V., England, G. W., \& Lofquist, L. H. (1967). Manual for the minnesota satisfaction questionnaire. Minnesota studies for vocational rehabilitation (No. XXII). Work Adjustment Project,. University of Minnesota Industrial Relations Center, Minneapolis, MN, 45-63.

58. Yavuz, M. (2010). The effects of teachers perception of organizational justice and culture on organizational commitment. African Journal of Business Management, 4(5), 695-701.

59. Zubair, A., Bashir, M., Abrar, M., Baig, S. A., \& Hassan, S. Y. (2015). Employee's Participation in Decision Making and Manager's Encouragement of Creativity. Journal of Service Science and Management, 8(03), 306-308. 